\title{
Measuring the Pro-Social Value System of Electrical Engineering Students
}

\section{Dr. Brock J. LaMeres, Montana Engineering Education Research Center}

Dr. Brock J. LaMeres is the Director of the Montana Engineering Education Research Center (MEERC) and an Associate Professor in the Department of Electrical \& Computer Engineering at Montana State University. LaMeres teaches and conducts research in the area of computer engineering. LaMeres is currently studying the effectiveness of online delivery of engineering content with emphasis on how the material can be modified to provide a personalized learning experience. LaMeres is also researching strategies to improve student engagement and how they can be used to improve diversity within engineering. LaMeres received his Ph.D. from the University of Colorado, Boulder. He has published over 80 manuscripts and 2 textbooks in the area of digital systems and engineering education. LaMeres has also been granted 13 US patents in the area of digital signal propagation. LaMeres is a member of ASEE, a Senior Member of IEEE, and a registered Professional Engineer in the States of Montana and Colorado. Prior to joining the MSU faculty, LaMeres worked as an R\&D engineer for Agilent Technologies in Colorado Springs, $\mathrm{CO}$ where he designed electronic test equipment.

\section{Prof. Jessi L. Smith, Montana State University}

Jessi L. Smith is Professor of Psychology at Montana State University. Her research specializes in social psychological aspects of gender and culture that utilizes models and theories to advance the success of people at risk in education, business, and health. 


\title{
Measuring the Pro-Social Value System of Electrical Engineering Students
}

\begin{abstract}
This paper presents the results of a study conducted at Montana State University (MSU) to measure the prosocial affordance beliefs about the electrical engineering (EE) profession in addition to prosocial trait endorsements of students in freshman and senior level EE classes. Goal-Congruity Theory states that students are more motivated to pursue a career when they believe the profession affords the values that they personally endorse. Goal-Congruity further categorizes value into two forms, agency (wealth, prestige, power), and prosocial (working with and helping others, benefitting society). In our study, we focus on the often-overlooked prosocial value. This type of value system is important for two reasons. First, with the ubiquitous nature of technology in the modern world, the consequence of engineering decisions can have a devastating impact on society, often in the aggregate over time. Considering the societal impact within the engineering decision making process can benefit the sustainability and accessibility of new technologies. Second, it has been shown that all students, both men and women, want careers that afford prosocial value, so framing curriculums in a way that highlights the benefit of working with others and helping society may propel student learning and increase retention into the workforce. Our study is additionally motivated by the fact that past research has shown that prosocial trait endorsement diminishes over time while in college (Cech, 2014). This means that there is an unknown mechanism in our engineering curriculums that is reinforcing the students' mindset that the impact of engineering decisions on society are secondary to other considerations. Our study seeks to replicate the findings of diminished prosocial trait endorsement while in college, but specifically looks at electrical engineering students. Our study further seeks to understand if beliefs about to extent to which the electrical engineering profession provides opportunities to fulfil prosocial goals also diminish overtime.
\end{abstract}

\section{Introduction}

In this study, we examine students' motivational processes that are shaped by social influences within the classroom. Motivation both propels student learning and also describes the willingness of a student to persist through the long process of engaging in a field (Harackiewicz, Smith \& Priniski, 2016). One relevant framework to the research in this study is the ExpectancyValue Theory of Motivation (Eccles, 1983). This theory breaks student motivation into two components. The first is expectancy, or how well a student believes they will do on a task. The second component is subjective task value, or how important, useful, or enjoyable the task is to the student. Much of the work in the area of expectancy-value has focused on the expectancy side of this equation by supporting students' feelings of competence, efficacy, and confidence (Lent, et al., 1996; Ponton, 2001). The research in this study instead pulls from the oftenoverlooked "value" component of motivation by specifically examining "utility value". When a student asks: "How is this job useful to me?" the answer predicts their motivation to persist in the field (Hullemann \& Harackiewicz, 2009; Harackiewicz et al., 2014).

To understand the different types and functions of work-values, our study draws from GoalCongruity Theory, which states people are more likely to pursue a career that affords the values they endorse (Diekman, et al., 2010). From the perspective of a student, there are two questions regarding value that are important. First, what values does the student personally hold dear? Second, what value does the student believe a specific career provides? When these two types of 
values are congruent, motivation improves. Goal congruity research has further found that there are generally two categories of values: agency (self-oriented, wealth, prestige) and prosocial (other-oriented, working with and helping others, benefitting society) (Thoman, et al. 2015; Diekman, et al., 2017). While it is certainly possible to view a profession as affording both agency and prosocial value, research on goal congruity finds that the majority of people desire professions that allow them to work with and help others. Further, the positive influence of prosocial value on motivation is more significant than that of agency values (e.g., Brown, Smith et al., 2015a; Thoman et al 2015b). Additionally, women, first generation college students, and underrepresented minorities (URMs) are especially attracted to professions that afford high levels of prosocial value (Morgan \& Sansone, 2001; Harackiewicz, et al., 2014; Smith, et al., 2014). This is partly because the social roles of these students tend to be those of caregivers, so they endorse prosocial traits as part of their identify (Diekman, et al., 2017; Bardi, et al., 2003; Priniski, et al., 2017). Thus, prosocial goal congruity, especially as a function of work-goal affordances, can spur motivation of all students, but especially those currently underrepresented in the engineering workforce (Thoman et al., 2015).

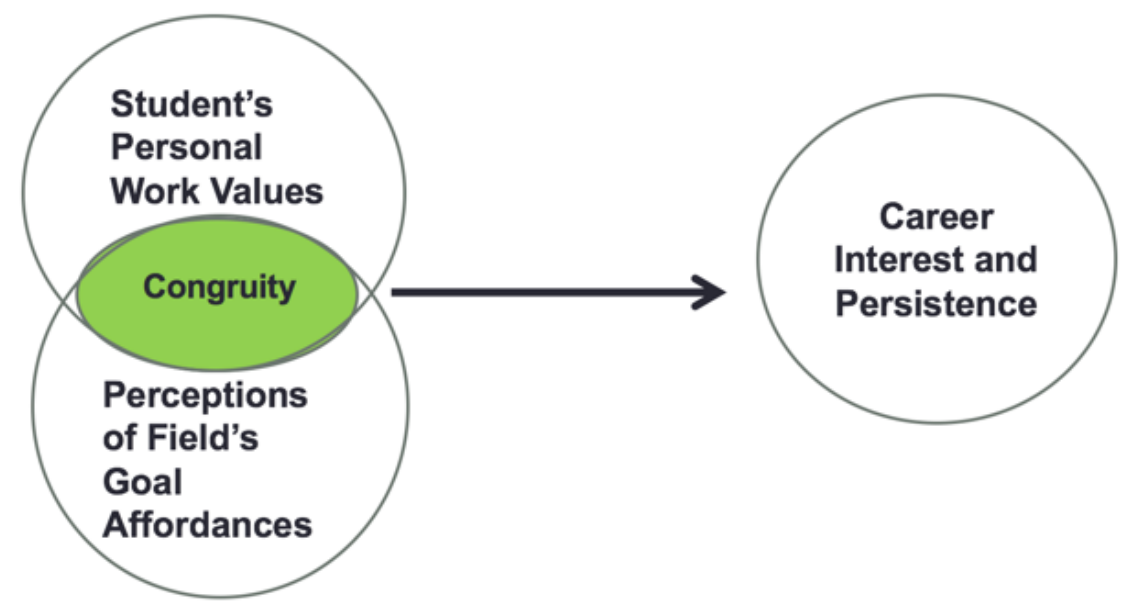

Figure 1. Goal-Congruency Model

The engineering profession is often misperceived as not affording prosocial value. Indeed, engineering embodies the stereotype of individuals working in isolation with a singular focus on technology (Cheryan, et al., 2013; 2015). While there are certainly parts of engineering that involve working alone, $21^{\text {st }}$ century engineering problems are predominantly solved by teams working collaboratively to create solutions that benefit others. Thus, the perception that engineering does not afford prosocial value (i.e., working with \& helping others) is mostly inaccurate.

This stereotype is concerning because goal congruity research shows the majority of people pursue careers that afford prosocial value. The inaccurate perception of the engineering workforce makes it unappealing to certain students (Boucher, et al., 2017). This is of further concern because people who wish to help others and benefit society are unattracted to engineering. This is in direct contrast to the call from the National Academy of Engineering to strengthen the workforce through broadening participation and considering engineering in a global context (NAE, 2004). 
Engineering is perceived as affording agentic values in that it can provide a career that brings wealth and prestige (Cheryan, et al., 2015). Perceptions of prosocial and agentic goal affordance of engineering are not mutually exclusive (i.e., students can believe the profession provides both). However, prosocial goal affordance is highlighted within goal-congruity theory because it is common to most students (Boucher, et al., 2017) and highly malleable (Brown, Thoman et al, 2015a; Brown, Smith, et al., 2015b).

Confounding the impact of misconceptions about the prosocial goal affordances of engineering is the diminished personal valuation of prosocial traits over time. In 2014, sociologist Erin Cech revealed a "culture of disengagement" in engineering (Cech, 2014). In this 5-year, longitudinal study of over 300 engineering students at 4 universities nation-wide, students rated their professional/ethical responsibility as engineers, their concern for understanding the consequences of technology, their degree of social consciousness, and their concern for understanding how people use machines. Ratings were collected twice during their college career and once 18 months following graduation. The results of Cech's study revealed that engineers, both as students and then when working in industry, showed a linear decline for concerns about public welfare across the time points. This report highlighted that engineering students over time showed diminished prosocial trait endorsement. Cech's findings further motivate the study of prosocial affordance beliefs about the engineering profession. If most students enter college with high personal prosocial traits and are more motivated to pursue careers that afford prosocial value, the formation of engineers is being hindered by compounding factors. The first factor is diminishing prosocial trait endorsement over time and the second factor is the stereotype about engineering being a profession that does not afford opportunities to fulfil prosocial goals.

In this study we seek to measure the prosocial beliefs and prosocial trait endorsements of students in an electrical engineering program at Montana State University. We seek to determine if diminished prosocial trait endorsement replicates within electrical engineering and collect new data on the prosocial affordance beliefs that students have about the electrical engineering profession.

\section{Method}

An online survey was designed and administered to students enrolled in a required freshmanlevel ( $\left.\mathrm{n}=79, \mathrm{M}_{\mathrm{age}}=19.97(\mathrm{SD}=2.02)\right)$ EE course and a required senior-level $(\mathrm{n}=51$, $\left.\mathrm{M}_{\mathrm{age}}=23.18(\mathrm{SD}=3.15)\right)$ EE course during the same academic year at MSU. In both classes, 60$65 \%$ were majoring in electrical engineering and 20-25\% were majoring in computer engineering. In both classes, $85-86 \%$ were male and $14-15 \%$ were female. The majority of students were white (no other races/ethnicities are able to be reported due to the low numbers leading to potential identification of the participant). Instruments from other studies that had been tested for reliability and validity were used to measure affordance beliefs about the EE profession (both prosocial and agentic), prosocial trait endorsement, and specific measures on the important of technical vs. professional skills in having a successful career in electrical engineering. A five-point Likert scale was used on all questions, with the exception of the instruments used to measure trait empathy, which used a 6-point Likert scale. The data was then coded and analyzed for any statistical significance $(\mathrm{p}<0.05)$ and direction against the midpoint using an independent T-Test and then any statistical significance between groups (freshman vs. seniors) was determined using between group T-Tests. A cover story was used to avoid experimenter/subject bias and the course instructor was unable to see the names of the participants. Each student received a \$10 amazon.com gift card for voluntarily participating in 
the survey and their participation did not impact their course grade. Attention checks were included throughout the survey and students not passing the checks were excluded from the results.

\section{Results}

Figure 2 shows the averages of the variables of interest in this study. The EE Agency Affordance Beliefs and Prosocial Affordance Beliefs represent variables measuring the student perceptions (i.e., stereotypes) about the value affordance of the EE profession. The Ethical Responsibilities and Empathic Concern represent variables measuring prosocial trait endorsement.

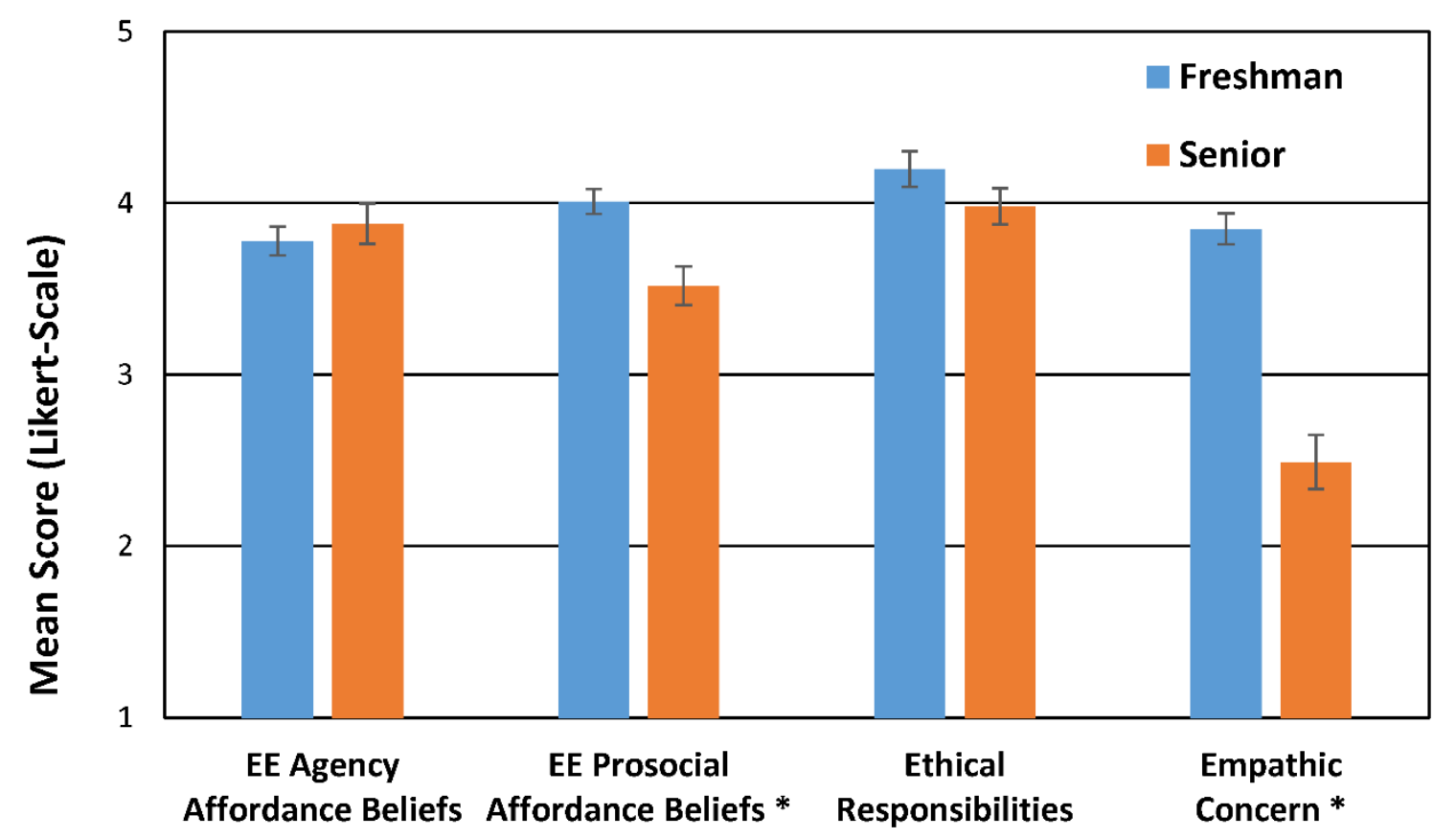

Note 1: Error bars are +/- 1x Standard Error.

Note 2: * Indicates statistically significant difference between groups $(p<0.05)$

Note 3: All measures are on 5-point Lilkert scale except Empathic Concern, which is on a 6-point scale.

Figure 2. Comparison of Affordance Beliefs and Prosocial Trait Endorsements across Freshman and Senior EE Students.

\section{$\underline{\text { EE Affordance Beliefs }}$}

Both freshman and seniors believed that the EE profession afforded agentic value significantly above the neutral point. Additionally, there was no statistical difference in agentic affordance beliefs between the freshmen and seniors.

Both freshmen and seniors also believed that the EE profession afforded prosocial value significantly above the neutral point. However, there was a statistically significant decline in the prosocial affordance beliefs of seniors compared to freshman. The mechanism of this decline is 
unclear. It could be that the EE curriculum is reinforcing the stereotype that the profession does not involve working with and helping others and benefitting society. It could also be that students entering the program with high prosocial affordance beliefs about the EE profession leave the degree before reaching their senior year. A longitudinal study is required to answer these questions.

\section{Prosocial Trait Endorsement}

Both freshman and seniors believed ethical responsibility was important to working as an electrical engineering. There was no statistical difference in ethical responsibility endorsement between the freshmen and seniors.

Empathic concern, however, showed a significant difference between freshman and seniors. Freshman were shown to believe empathy was an important trait to working as an electrical engineer while seniors did not. Seniors' concern for empathy was not only significantly below freshman, but also significantly below the neutral point.

Instruments were also used to gain an understanding of how students viewed the importance of technical skills versus engagement skills (often called professional skills) to having a successfully career in EE. The following plot shows the results of the entire group of students $(\mathrm{N}=130)$. There was no difference between freshman and seniors in these results, so the averages are given for the entire group. All questions were given on a 5-point Likert scale.

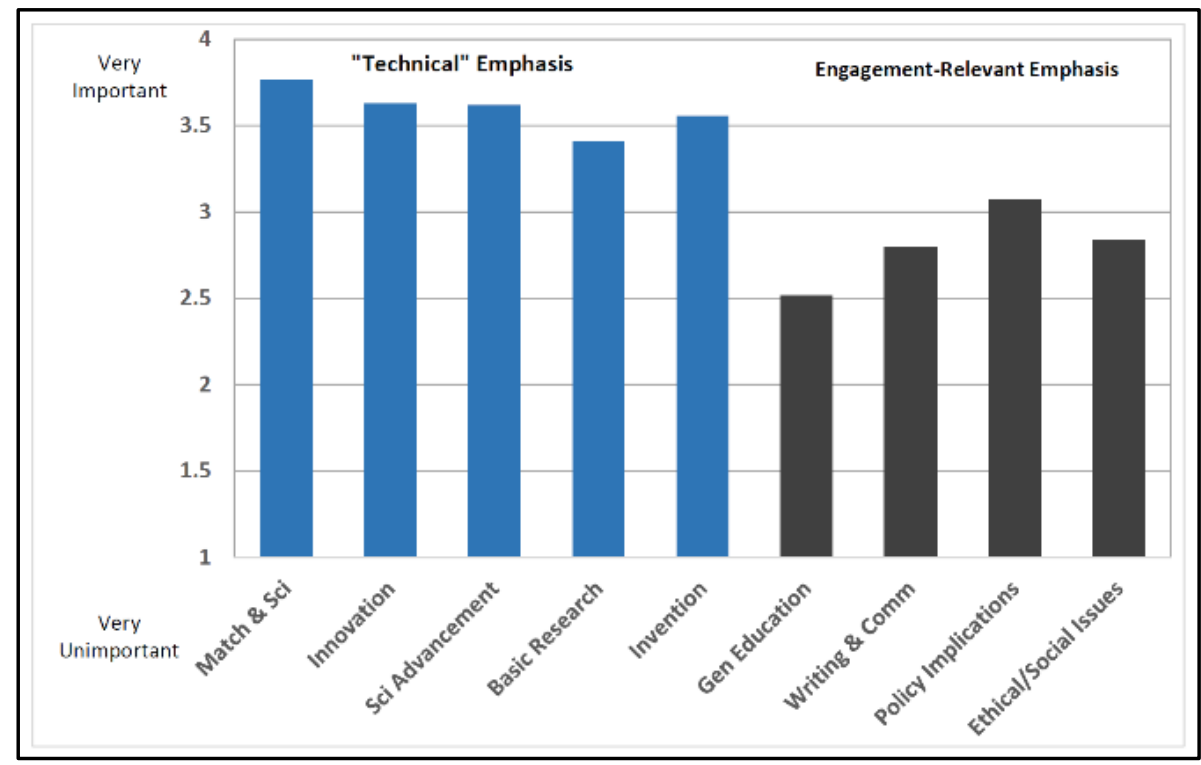

Figure 3. Student Perceiptions of the Relative Value of Technical vs. Engagement-Related Skills.

These results replicate Cech's findings that engineering students perceive technical skills to be more important to having a successful career, but specifically within electrical engineering. 


\section{Conclusion}

The results in this study reveal a disturbing trend in the value system of electrical engineering students. First, students are displaying both diminishing levels of prosocial affordance beliefs while simultaneously exhibiting diminishing levels of prosocial trait endorsement. This is of great concern to the formation of engineers because Goal-Congruity Theory states that people are more likely to pursue careers that afford values that they personally endorse. It further states that all students have been shown to want careers with prosocial value, thus these two variables are working together to make electrical engineering a profession that is unappealing to the majority of students. Second, the fact that seniors show low levels of prosocial value (both affordance beliefs and trait endorsements) is concerning because these are the engineers about to enter the workforce. As such, they are the ones making engineering decisions that impact society and also serving as the role models for the profession. This means their low prosocial value may serve to reinforce the beliefs that electrical engineering is a profession that does not allows people to work with and help others, and benefit society. If we want to ensure that the engineering workforce of tomorrow holds public welfare paramount and attracts a diverse population, steps need to be taken in higher education to address this culture of pro-social disengagement.

\section{References}

Bardi, A., \& Schwartz, S. H. (2003). "Values and behavior: Strength and structure of relations,” Personality and Social Psychology Bulletin, vol. 29, no. 10, pp. 1207-1220, 2003.

Boucher, K. L., Fuesting, M. A., Diekman, A. B. \& Murphy, M. C. (2017). "Can I Work with and Help Others in This Field? How Communal Goals Influence Interest and Participation in STEM Fields,” Frontiers in Psychology, vol. 31, May 2017.

Brown, E. R., Smith, J. L., Thoman, D. B., Allen, J. \& Muragishi, G. (2015b). "From bench to bedside: A communal utility value intervention to enhance students' science motivation," Journal of Educational Psychology, vol. 107, no. 4, pp. 1116-1135, Nov. 1, 2015.

Cheryan, S., Plaut, V. C., Handron, C. \& Hudson, L. (2013). "The Stereotypical Computer Scientist: Gendered Media Representations as a Barrier to Inclusion for Women”, Sex Roles, vol. 69, pp. 5871, June 22, 2013.

Cheryan, S., Master, A. \& Meltzoff, A. N. (2015). “Cultural stereotypes as gatekeepers: increasing girls’ interest in computer science and engineering by diversifying stereotypes," Frontiers in Psychology, no. 11, Feb. 2015.

Cech, E.A. (2014). “Culture of Disengagement in Engineering Education?,” Science Technology Human Values. vol. 39, no. 1, pp. 42-72. 2014.

Diekman, A. B., Brown, E. R., Johnston, M. A., \& Clark, E. K. (2010). "Seeking congruity between goals and roles: A new look at why women opt out of science, technology, engineering, and mathematics careers,” Psychological Science, vol. 21, pp. 1051-1057, 2010.

Diekman, A. B., Steinberg, M., Brown, E. R., Belanger, A. L., \& Clark, E. K., (2017). “A Goal Congruity Model of Role Entry Engagement, and Exit: Understanding Communal Goal Processes in STEM Gender Gaps, "Personality and Social Psychology Review, vol. 21, no. 2, pp. 142-175, 2017.

Eccles (Parsons), J. (1983). "Expectations, values and academic behaviors," in Achievement and achievement motivation. San Francisco, CA, W. H. Freeman Publishing, 1983.

Harackiewicz, J. M., Canning, E. A., Tibbetts, Y., Giffen, C. J., Blair, S. S., Rouse, D. I., \& Hyde, J. S. (2014). "Closing the social class achievement gap for first-generation students in undergraduate biology,” Jnl of Educational Psychology, vol. 106, no. 2, pp. 375-389, 2014.

Harackiewicz, J.M., Smith, J. L. \& Priniski, S.J. (2016). “The Importance of Promoting Interest in Education,” Policy Insights from the Behavioral and Brain Sciences, vol. 3, no. 2, June 2016.

Hullemann, C. S. \& Harackiewicz, J. M. (2009). "Promoting Interest and Performance in High School Science Classes,” Science, vol. 326, no. 5958, pp. 1410-1412, Dec. 2009. 
Lent, R. W. (1996). “A social cognitive framework for studying career choice and transition to work,” Jnl of Vocational Educational Research, vol. 21, no. 4, pp. 3-31, 1996.

Morgan, C., Isaac, J. D., \& Sansone, C. (2001). "The role of interest in understanding the career choices of female and male college students,” Sex Roles, vol. 44, pp. 295-320. 2001.

National Academy of Engineering. (2004). "The Engineer of 2020: Visions of Engineering in the New Century,” National Academies Press, Washington, D.C, 2004.

Ponton, M. K., Edmister, J. H., Ukeiley, L. S. \& Seiner, J. M. (2001). "Understanding the role of selfefficacy in engineering education,” Jnl of Engineering Education, vol. 90, no. 2, pp. 247-251, 2001.

Priniski, S. J., Hecht, C. A. \& Harackiewicz, J. M. (2017). "Making Learning Personally Meaningful: A New Framework for Relevance Research,” The Jnl of Experimental Education, vol. 86, no. 1, October 18, 2017.

Smith, J. L., Cech, E., Metz, A., Huntoon, M. \& Moyer, C. (2014). “Giving back or giving up: Native American student experiences in science and engineering,” Cultural Diversity \& Ethnic Minority Psychology, vol. 20, no. 3, pp. 413-429, July 2014.

Thoman, D. B., Brown, E. R., Mason, A. Z., Harmsen, A. B. \& Smith, J. L. (2015). "The Role of Altruistic Values in Motivating Underrepresented Minority Students for Biomedicine,” BioScience, vol. 65, no. 2, pp. 183-188, 2015. 